Original Article

\title{
Nasopharyngeal Microbiome Composition is Different Among Children with Bronchial Asthma
}

\author{
Christine W.S. Basanti1*, Magd A. Kotb", Amal M. Sayed ${ }^{2}$, May Abdelfattah'2, \\ Mohamed Ghanem ${ }^{3}$, Azza K. Abdelmegeid ${ }^{1}$
}

1 Department of Pediatrics, Faculty of Medicine, Cairo University, Egypt; christine.w.shaker@gmail.com, magdkotb@kasralainy.edu.eg, azzakamal1718@gmail.com

2 Department of Clinical and Chemical Pathology, Faculty of Medicine, Cairo University, Egypt; aml.said@kasralainy.edu.eg, mayabdelfattah@kasralainy.edu.eg

3 Department of Pediatrics, Al Anfoshy General Hospital, Alexandria, Egypt;

dr.mohamed.ghanem88@gmail.com

* Correspondence: christine.w.shaker@gmail.com

Received: 6/5/2021; Accepted: 11/6/2021; Published online: 25/6/2021.

\begin{abstract}
:
Background: The microbiome composition is as unique and diverse as humans are; it may vary substantially over time. A stable microbiome is essential for immune development, while dysbiosis in the microbiome has been associated with an increased risk for asthma and allergies. Knowledge about nasopharyngeal microbiome among Egyptian children with asthma is lacking. Aim of the work: To study the nasopharyngeal microbiome in a group of Egyptian asthmatic children, and to compare it to a group of healthy controls of similar age and sex distribution.

Subjects and Methods: A cross-sectional case-control study was performed on 60 Egyptian children aged 1-13 years. Of those, 30 children suffered un-exacerbated asthma, and 30 children were healthy controls. Nasopharyngeal swabs were obtained from all participants and the nasopharyngeal microbiome was identified using the VITEK 2 system after primary organism isolation by routine cultures.

Results: A statistically significant difference was found for the overall microbiome composition between asthmatic and control children $(\mathrm{p}=0.007)$. The most common combination of organisms in asthmatics was Staphylococcus aureus and Streptococcus pneumoniae, and was statistically higher than in controls (0.038). Normal controls had a higher incidence of presence of coagulase negative staphylococci (30\%) than the asthmatic group (3.3\%) (p-0.009). Kocuria rosea, although present more in asthmatics, the difference did not reach statistical significance. However, within the asthmatic group, the presence of $K$. rosea was noted more in patients with more severe asthma $(\mathrm{p}=0.02)$.

Conclusion: The microbiome composition in a group of asthmatic Egyptian children was different from that of healthy controls. Whether this difference has a causative relation to asthma development /severity, or is due to upregulation of certain species to combat certain environmental hazards was beyond the scope of this study and awaits further research.
\end{abstract}

Level of Evidence of Study: IIB (1).

Keywords: bronchial asthma; children; microbiome; nasopharyngeal

Abbreviations: CONS: Coagulase negative staphylococci; CS: Caesarean section; ICS: Inhaled corticosteroids; NICU: Neonatal intensive care unit; NVD: Normal vaginal delivery; prn: Pro re nata (taken as needed); SABA: Short acting beta 2 agonist; SD: Standard deviation.

\section{Introduction}

Bronchial asthma is a chronic inflammatory airway disease characterized by hyperresponsiveness and episodic obstruction of the bronchi in response to various triggers. Asthma triggers include food, exercise and environmental factors such as polluted air and others (2). The determinants of the personal susceptibility to asthma are variable. The microorganism aggregates that dwell in the nasopharynx and the lung, as well as on the skin and mucosa of other systems (known as the microbiome) are vital for training of the immune system. They 
provide symbiotic support for regulation or symbiotic dysregulation of the immune response (3). The microbiome includes whole viruses, virus genomes, bacteria, archaea and other eukaryotes of the lungs and gut. They are linked in the gut-lung floral axis and both influence the $\mathrm{T}$ helper immune response (4). The microbiome-human interaction is defined by the types of food, the composition and concentration of micronutrients, substrates, the cellular metabolism, the resulting metabolic end-products as well as the geographic location (5). The microbiome dysbiosis (imbalance) and the metabolomics (how metabolites interact with the biological system) were noted to influence asthma severity and response to therapeutic agents (6). There has been no studies to date about the nasopharyngeal microbiome in Egyptian children. One study involved the nasal microbiome of adult males in rural and industrial areas (5), and several other research articles studied the gut microbiome in various conditions in adults (7-9). The work at hand aimed to study the composition of the nasopharyngeal microbiome among a cohort of Egyptian children with bronchial asthma, and to compare it to that of healthy controls of similar age and sex distribution.

\section{Subjects and Methods}

This cross sectional study was carried out at Cairo University Children's Hospitals. The Pediatric Department Committee of Research and Higher Studies Research Committee of Faculty of Medicine, Cairo University approved the study, in compliance to Helsinki declaration guidelines (10).

\section{Participants}

The study included 60 children; 30 known asthmatics, aged 1-13 years old, diagnosed and following up in Allergy and Pulmonology Clinic at Cairo University Children's Hospital, as well as 30 age and sex matched non-asthmatic healthy children as a control group. Any child with acute upper respiratory tract infection at time of examination, or any other acute or chronic chest conditions apart from bronchial asthma were excluded. In addition, any child who received antibiotics in the two weeks preceding the swab was excluded. Asthmatic patients of any severity level were included (according to National Heart, Lung and Blood Institute 2017 guidelines) (11), but they were not in an exacerbation at the time of nasopharyngeal swabbing.

\section{Methods}

An informed consent was obtained from the parent/guardian of the included children. All included patients were subjected to detailed history taking, clinical and chest examination. Nasopharyngeal swabs were obtained from all children; patient and controls.

Nasopharyngeal swab procedure and culturing

The physician obtaining the swab wore sterile gloves and used a Dacron swab inserted slowly through the nostril to the posterior pharynx. Ideally, the swab was left in the posterior pharynx for 10 seconds before withdrawing. Optimal sampling and handling of the specimen was done to improve the rate of recovery of different microorganisms. Then the specimen was cultured on ordinary routine cultures for isolation and identification of the nasopharyngeal microbiome.

\section{Microbiota identification}

The nasopharyngeal swab was then cultured routinely, isolation and identification of the organisms was then done first by light microscopy and then by VITEK 2 system (bioMérieux, USA). The VITEK 2 system is a fully automated, extended-database system for bacterial and fungal identification and antibiotic sensitivity. Handling was minimized in a simple standardized inoculum. The inoculum was placed into the VITEK 2 Cassette, the VITEK 2 Card and sample were linked virtually. Once the Cassette was loaded, the incubation and reading of each card was managed by the system without any intervention. VITEK 2 could provide identification results in as little as 5 hours. The VITEK cards have 64 wells with various nutrients and biochemical tests. The inoculated microorganism reacts within the card creating a pattern of positive and negative reactions. This pattern is then compared automatically to a built-in library of database providing a name for the bacteria or fungus. 


\section{Statistical Analysis}

For data analysis, the IBM SPSS V. 22.0 statistics program (IBM Corp., USA, 2013) was used. Data were tabulated as quantitative and qualitative data, where parametric and nonparametric data analysis was employed respectively. Standard student T-test was used for the comparison between the parametric data of the two groups. The calculated "t" was compared with the tabulated one at different levels of significance at the degree of freedom. Chi-square test of significance was used between the two groups as regards the qualitative data. A p-value less than 0.05 denoted statistical significance.

\section{Results}

Both the 30 children with bronchial asthma recruited from the Allergy and Pulmonology Clinic, and the control group had comparable age, sex and residential background. At enrollment, the children with asthma had a mean age (+/- standard deviation) of $5.67 \pm 3.3$ years, while the mean age of the control group was $5.1 \pm 3$ years $(\mathrm{p}=0.45)$. The group with asthma comprised 13 girls and 17 boys while the control group comprised 12 girls and 16 boys $(\mathrm{p}=0.5)$. There was also no statistically significant difference regarding their residential background $(p=0.79)$ (Table 1$)$.

Table 1: Demographic characteristics of the studied groups.

\begin{tabular}{|c|c|c|c|}
\hline & Cases $(\mathrm{N}=30)$ & Controls $(\mathrm{N}=30)$ & $P$ value \\
\hline \multicolumn{4}{|l|}{ Age (years) } \\
\hline Mean +/- SD & 5. $67 \pm 3.3$ & $5.1 \pm 3$ & \multirow{2}{*}{0.45} \\
\hline Median (range) & $5(1.1-13)$ & $4(1.3-12)$ & \\
\hline \multicolumn{4}{|c|}{ Gender (number, \%) } \\
\hline Females & $13(43.33 \%)$ & $12(40 \%)$ & \multirow{2}{*}{0.5} \\
\hline Males & $17(56.67 \%)$ & $18(60 \%)$ & \\
\hline \multicolumn{4}{|c|}{ Residence (number, \%) } \\
\hline Rural & $7(23.33 \%)$ & $11(36.67 \%)$ & \multirow{2}{*}{0.79} \\
\hline Urban & $23(76.67 \%)$ & $19(63.33 \%)$ & \\
\hline
\end{tabular}

Sixteen asthmatic (53.33\%) patients had positive family history of asthma, half the asthmatic children had history of household smoking, and only $13.33 \%$ had history of animal contact. Perinatal history, asthma severity, medications and hospitalization history are listed in Table 2.

The various organisms and organism combinations detected in the nasopharyngeal swabs of all the recruited children, had a significant difference in the overall composition between patients and controls $(\mathrm{p}=0.007)$ (Table 3). The combination of Staph. aureus and Strep. pneumoniae was only present among asthmatics (4 patients) but not controls $(\mathrm{p}=0.038)$. The presence of each organism (whether detected alone or in combination) is then shown in table 4 as absolute numbers and percentages to total patients and controls. The results of patients are contrasted to those of controls, showing coagulase negative staphylococci (CONS) to be more predominant in controls (9 controls versus one patient) $(\mathrm{p}=0.009)$.

Next, we compared the asthmatic patients who had the combination of Staph. aureus and Strep. pneumoniae with asthmatics who didn't have this combination in terms of various factors (Table 5) with no significant differences.

Similarly, there was no significant difference between patients who had diphtheroids and those who did not, in terms of age $(0.24)$, sex $(p=0.61)$, animal contact $(p=0.71)$, smoking $(p=0.34)$, positive family history for asthma $(\mathrm{p}=0.15)$, asthma severity $(\mathrm{p}=0.28)$, number of medications used $(p=0.72)$, hospitalizations for asthma $(p=0.48)$, mode of delivery $(p=0.64)$, history of NICU admission $(\mathrm{p}=0.43)$, nor feeding pattern $(\mathrm{p}=0.47)$. 
Table 2: Risk factors, perinatal history, asthma severity, medications used and hospitalizations among the studied asthmatic children.

\begin{tabular}{lcc}
\hline Risk Factors & Number & $\%$ \\
\hline Positive family history & 16 & 53.33 \\
\hline Passive smoking & 15 & 50 \\
\hline Animal contact & 4 & 13.33 \\
\hline Perinatal History & & \\
\hline Delivery by Caesarian section & 22 & 73.33 \\
\hline NICU admission & 4 & 13.33 \\
\hline Exclusive breast feeding & 19 & 63.33 \\
\hline Asthma Severity & & \\
\hline Intermittent & 5 & 16.67 \\
\hline Mild persistent & 7 & 23.33 \\
\hline Moderate persistent & 10 & 33.33 \\
\hline$\quad$ Severe persistent & 8 & 26.67 \\
\hline Medications Used & \multicolumn{2}{c}{} \\
\hline$\quad$ Short acting beta two agonists (SABA) as needed (prn) & 5 & 8.33 \\
\hline SABA (prn) \& controller inhaled corticosteroids (ICS) & 16 & 26.67 \\
\hline SABA (prn) \& controller ICS + monteleukast & 7 & 11.67 \\
\hline SABA (prn) \& controller ICS + monteleukast + oral corticosteroids & 2 & 6.67 \\
\hline Hospitalizations for asthma & 17 & 56.67 \\
\hline
\end{tabular}

*Asthma Severity, according to National Heart, Lung and Blood Institute, 2007 (11).

Table (3): The detected organism/combinations in the nasopharyngeal swabs.

\begin{tabular}{|c|c|c|c|c|}
\hline & $\begin{array}{c}\text { Cases } \\
(N=30)\end{array}$ & $\begin{array}{c}\text { Controls } \\
(\mathrm{N}=30)\end{array}$ & $\begin{array}{c}P \\
\text { value }\end{array}$ & $\begin{array}{c}\text { Overall } \\
\boldsymbol{P} \\
\text { value }\end{array}$ \\
\hline CONS * & 0 & $5(16.67 \%)$ & 0.045 & \multirow{22}{*}{0.007} \\
\hline Diphteroids & $3(10 \%)$ & $4(13.33 \%)$ & 0.68 & \\
\hline Diphteroids, CONS* \& Candida & 0 & $1(3.33 \%)$ & 0.31 & \\
\hline Diphteroids, K. rosea*, G. elegans* & 0 & $1(3.33 \%)$ & 0.31 & \\
\hline Diphteroids \& CONS* & 0 & $1(3.33 \%)$ & 0.31 & \\
\hline Diphteroids \& Anthracoids & $1(3.33 \%)$ & 0 & 0.31 & \\
\hline Diphteroids \& Candida & $1(3.33 \%)$ & 0 & 0.31 & \\
\hline K. rosea $^{*} \&$ Acinetobacter & $1(3.33 \%)$ & 0 & 0.31 & \\
\hline K. rosea* & $4(13.33 \%)$ & $3(10 \%)$ & 0.68 & \\
\hline K. rosea* \& Anthracoids & 0 & $1(3.33 \%)$ & 0.31 & \\
\hline $\begin{array}{l}\text { K. rosea* }{ }^{*} \text { D. nishinomiyaensis* }, K . \\
\text { sedentarius*, Diphteroids \& G. elegans* }\end{array}$ & $1(3.33 \%)$ & 0 & 0.31 & \\
\hline K. rosea* \& Diphteroids & $2(6.67 \%)$ & 0 & 0.15 & \\
\hline K. rosea*, Diphteroids \& G. elegans* & $1(3.33 \%)$ & 0 & 0.31 & \\
\hline $\begin{array}{l}\text { K. rosea* \& }, K . \text { varians, } \\
\text { D. nishinomiyaensis* \& K. sedentarius* }\end{array}$ & $1(3.33 \%)$ & 0 & 0.31 & \\
\hline Staph. * aureus & $5(16.67 \%)$ & $6(20 \%)$ & 0.73 & \\
\hline Staph. * aureus, CONS* & $1(3.33 \%)$ & $1(3.33 \%)$ & NA & \\
\hline Staph. * aureus \& Diphteroids & $1(3.33 \%)$ & $2(6.67 \%)$ & 0.55 & \\
\hline Staph. ${ }^{*}$ aureus \& Strept. ${ }^{*}$ pneumoniae & $4(13.33 \%)$ & 0 & 0.038 & \\
\hline Strep. ${ }^{*}$ pneumoniae & $3(10 \%)$ & $4(13.33 \%)$ & 0.68 & \\
\hline Strep. ${ }^{*}$ pneumoniae \& Acinetobacter & 0 & $1(3.33 \%)$ & 0.31 & \\
\hline Strep. ${ }^{*}$ pneumoniae \& Strep. * pseudoporcinus & $1(3.33 \%)$ & 0 & 0.31 & \\
\hline Strep. ${ }^{*}$ pneumoniae, CONS * & 0 & $1(3.33 \%)$ & 0.31 & \\
\hline
\end{tabular}

CONS: Coagulase Negative Staphylococcus; D. nishinomiyaensis: Dermacoccus nishinomiyaensis; G. elegans: Granulitella elegans; K. rosea: Kocuria rosea; K. sedentarius: Kytococcus sedentarius; K. varians: Kocuria varians; N: number; Staph,: Staphylococcus; Strep.: Streptococcus. 
Table 4: The frequency of individual organisms in the nasopharyngeal swab of the included children.

\begin{tabular}{lccc}
\hline & $\begin{array}{c}\text { Cases } \\
(\mathbf{N}=30)\end{array}$ & $\begin{array}{c}\text { Controls } \\
(\mathbf{N}=30)\end{array}$ & P value \\
\hline CONS (Coagulase Negative Staphylococcus) & $1(3.33 \%)^{*}$ & $9(30 \%)$ & 0.009 \\
\hline Diphteroids & $9(30 \%)$ & $6(20 \%)$ & 0.27 \\
\hline Staphylococcus aureus & $11(36.67 \%)$ & $8(26.67 \%)$ & 0.28 \\
\hline Streptococcus pneumoniae & $8(26.67 \%)$ & $6(20 \%)$ & 0.38 \\
\hline Kocuria rosea & $10(30 \%)$ & $4(13.33 \%)$ & 0.06 \\
\hline Candida & $1(3.33 \%)$ & $1(3.33 \%)$ & $\cdots$ \\
\hline Granulitella elegans & $1(3.33 \%)$ & $1(3.33 \%)$ & $\cdots$ \\
\hline Anthracoids & $1(3.33 \%)$ & $1(3.33 \%)$ & $\cdots$ \\
\hline Acinetobacter & $1(3.33 \%)$ & 0 & 0.31 \\
\hline Dermacoccus nishinomiyaensis & $1(3.33 \%)$ & 0 & 0.31 \\
\hline
\end{tabular}

*Data are presented as: number (percentage). Multiple organisms could be found within the same patient and thus the totals exceed $100 \%$. N: number.

There was no significant difference between patients who had Staph. aureus per se and those who did not in terms of age $(0.34)$, sex $(p=0.7)$, animal contact $(p=0.47)$, smoking $(p=0.064)$, positive family history for asthma $(\mathrm{p}=0.109)$, asthma severity $(\mathrm{p}=0.69)$, number of medications used $(\mathrm{p}=0.72)$, hospitalizations for asthma $(\mathrm{p}=0.16)$, mode of delivery $(\mathrm{p}=0.24)$, history of NICU admission $(\mathrm{p}=0.26)$, nor feeding pattern $(\mathrm{p}=0.55)$.

Table 5: Staph. aureus and Strep. pneumoniae distribution among the asthmatic children.

\begin{tabular}{|c|c|c|c|}
\hline & $\begin{array}{l}\text { Staph. aureus and } \\
\text { Strep. pneumoniae } \\
(\mathrm{N}=4)\end{array}$ & $\begin{array}{l}\text { None } \\
(\mathrm{N}=26)\end{array}$ & $\begin{array}{c}P \\
\text { value }\end{array}$ \\
\hline \multicolumn{4}{|l|}{ Age in years } \\
\hline Mean \pm SD & $4.2 \pm 3.3$ & $5.9 \pm 3.2$ & \multirow{2}{*}{0.34} \\
\hline Median (range) & $4(1.1-13)$ & $5(1.3-12)$ & \\
\hline \multicolumn{4}{|l|}{ Gender } \\
\hline Male & $2(50 \%)$ & $15(57.7 \%)$ & \multirow{2}{*}{0.59} \\
\hline Female & $2(50 \%)$ & $11(42.3 \%)$ & \\
\hline Animal Contact & $1(25 \%)$ & $3(11.5 \%)$ & 0.45 \\
\hline Smoking & $2(50 \%)$ & $13(50 \%)$ & NA \\
\hline Family history & $1(25 \%)$ & $3(50 \%)$ & 0.35 \\
\hline \multicolumn{4}{|l|}{ Asthma Severity } \\
\hline Intermittent asthma & $3(75 \%)$ & $17(65.4 \%)$ & \multirow{4}{*}{0.83} \\
\hline Mild persistent & $1(25 \%)$ & $7(26.9 \%)$ & \\
\hline Moderate persistent & $\begin{array}{c}1 \\
0\end{array}$ & $2(6.7 \%)$ & \\
\hline Severe persistent & 0 & 0 & \\
\hline \multicolumn{4}{|l|}{ Medications } \\
\hline SABA & & & \multirow{5}{*}{0.88} \\
\hline SABA \& ICS & $1(25 \%)$ & $8(30.8 \%)$ & \\
\hline SABA \& ICS \& Monteleukast & $3(75 \%)$ & $15(57.7 \%)$ & \\
\hline SABA\& ICS \& Montleukast \& & 0 & $1(3.3 \%)$ & \\
\hline oral corticosteroids & & $2(7.7 \%)$ & \\
\hline Hospitalization* for asthma & $2(50 \%)$ & $15(57.7 \%)$ & 0.59 \\
\hline \multicolumn{4}{|l|}{ Mode of delivery } \\
\hline NVD & $2(50 \%)$ & $6(23.1 \%)$ & \multirow[t]{2}{*}{0.24} \\
\hline $\mathrm{CS}$ & $2(50 \%)$ & $20(76.9 \%)$ & \\
\hline NICU admission & $0(0 \%)$ & $4(15.4 \%)$ & 0.71 \\
\hline \multicolumn{4}{|l|}{ Feeding pattern } \\
\hline Breast & $2(50 \%)$ & $17(65.4 \%)$ & \multirow{3}{*}{0.55} \\
\hline Bottle & $1(25 \%)$ & $7(26.9 \%)$ & \\
\hline Breast \& bottle & $1(25 \%)$ & $2(6.7 \%)$ & \\
\hline
\end{tabular}

CS: Caesarean section; ICS: $\quad$ inhaled corticosteroids; NVD: normal vaginal delivery; SABA: short acting beta 2 agonists; N: number; SD: standard deviation. Hospitalization*: history of hospital admission at least once. 
Again, there was no significant difference between patients who had and those who did not have Strep. pneumoniae per se in terms of age $(0.22)$, sex $(p=0.48)$, animal contact $(p=0.71)$, smoking $(\mathrm{p}=0.34)$, positive family history for asthma $(\mathrm{p}=0.15)$, asthma severity $(\mathrm{p}=0.28)$, number of medications used $(p=0.72)$, hospitalizations for asthma $(p=0.48)$, mode of delivery $(p=0.64)$, history of NICU admission ( $\mathrm{p}=0.43)$, nor feeding pattern $(\mathrm{p}=0.96)$. The only organism that showed some significant findings was Kocuria rosea (Table 6).

Table 6: Distribution of Kocuria rosea among studied children with bronchial asthma.

\begin{tabular}{|c|c|c|c|}
\hline & $\begin{array}{c}\text { Kocuria rosea } \\
(\mathrm{N}=10)\end{array}$ & $\begin{array}{l}\text { None } \\
(\mathrm{N}=\mathbf{2 0})\end{array}$ & $P$ value \\
\hline \multicolumn{4}{|l|}{ Age in years } \\
\hline Mean \pm SD & $3.6 \pm 1.7$ & $6.7 \pm 3.9$ & \multirow[t]{2}{*}{0.012} \\
\hline Median (range) & $4(1.1-13)$ & $6(1.3-12)$ & \\
\hline \multicolumn{4}{|l|}{ Gender } \\
\hline Male & $6(60 \%)$ & $11(55 \%)$ & \multirow{2}{*}{0.55} \\
\hline Female & $4(40 \%)$ & $9(45 \%)$ & \\
\hline Animal Contact & $2(20 \%)$ & $2(10 \%)$ & 0.41 \\
\hline Smoking & $5(50 \%)$ & $10(50 \%)$ & 0.65 \\
\hline Family history & $6(60 \%)$ & $8(40 \%)$ & 0.25 \\
\hline \multicolumn{4}{|l|}{ Asthma Severity } \\
\hline Intermittent asthma & 0 & $5(25 \%)$ & \multirow{4}{*}{0.02} \\
\hline Mild persistent & $5(50 \%)$ & $6(30 \%)$ & \\
\hline Moderate persistent & $1(10 \%)$ & $5(25 \%)$ & \\
\hline Severe persistent & $4(40 \%)$ & $4(20 \%)$ & \\
\hline \multicolumn{4}{|l|}{ Medications } \\
\hline SABA & 0 & $5(25 \%)$ & \multirow{4}{*}{0.034} \\
\hline SABA \& ICS & $6(60 \%)$ & $10(50 \%)$ & \\
\hline SABA \& ICS \& Monteleukast & $2(20 \%)$ & $5(25 \%)$ & \\
\hline $\begin{array}{l}\text { SABA\& ICS \& Montleukast \& } \\
\text { oral corticosteroids }\end{array}$ & $2(20 \%)$ & 0 & \\
\hline Hospitalization for asthma & $8(80 \%)$ & $5(25 \%)$ & 0.006 \\
\hline \multicolumn{4}{|l|}{ Mode of delivery } \\
\hline NVD & $3(30 \%)$ & $5(25 \%)$ & \multirow[t]{2}{*}{0.54} \\
\hline $\mathrm{CS}$ & $7(70 \%)$ & $15(75 \%)$ & \\
\hline NICU admission & $4(40 \%)$ & $0(0 \%)$ & 0.01 \\
\hline \multicolumn{4}{|l|}{ Feeding pattern } \\
\hline Breast & $6(60 \%)$ & $13(65 \%)$ & \multirow{3}{*}{0.95} \\
\hline Bottle & $3(30 \%)$ & $5(25 \%)$ & \\
\hline Breast \& bottle & $1(10 \%)$ & $2(10 \%)$ & \\
\hline
\end{tabular}

CS: Caesarean section; ICS: inhaled corticosteroids; NVD: normal vaginal delivery; SABA: short acting beta 2 agonists; N: number; SD: standard deviation.

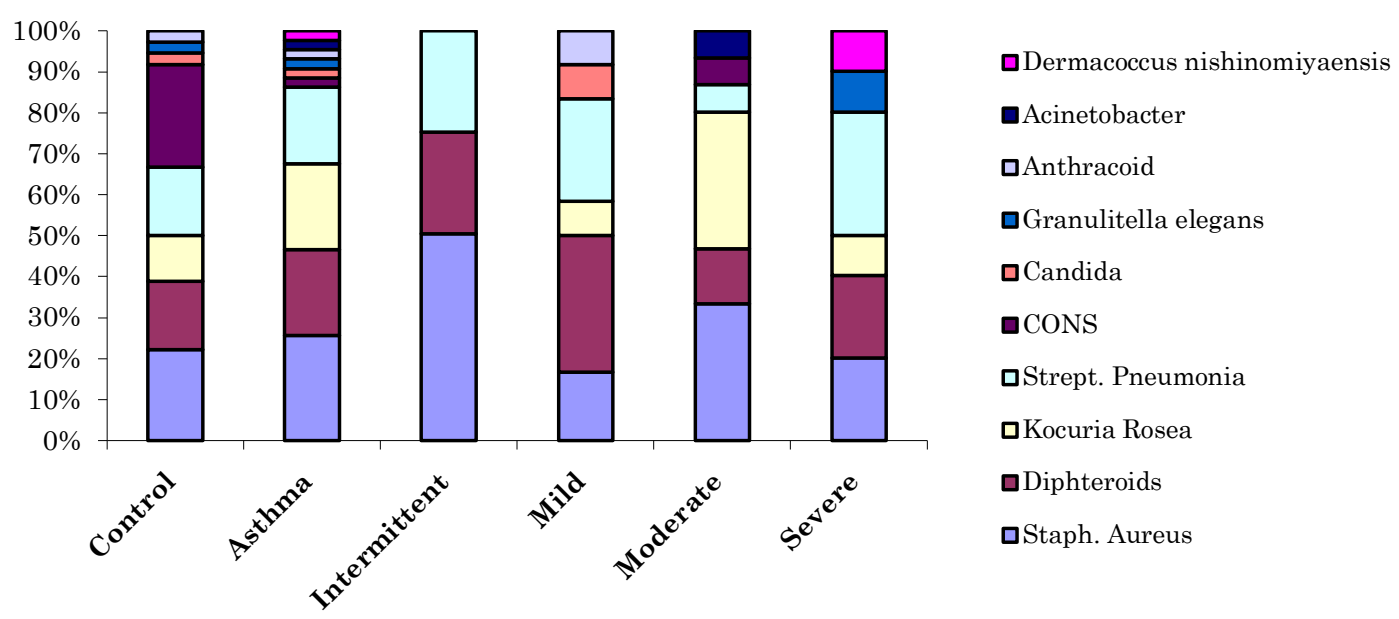

Figure 1: Nasopharyngeal microbiome relative composition in controls and asthmatics according to severity. 
Table 7: Composition of microbiome nasopharyngeal swabs of asthmatic patients according to residence.

\begin{tabular}{|c|c|c|c|c|c|c|c|}
\hline \multirow[b]{2}{*}{$\begin{array}{l}\text { Organism } \\
\text { (number in both urban } \\
\text { and rural patients) }\end{array}$} & \multicolumn{3}{|c|}{ Urban patients $(\mathrm{N}=18)$} & \multicolumn{3}{|c|}{ Rural patients $(\mathrm{N}=12)$} & \multirow[t]{2}{*}{$P$ value } \\
\hline & $\begin{array}{l}\text { Number of } \\
\text { urban } \\
\text { residents } \\
\text { having } \\
\text { organism }\end{array}$ & $\begin{array}{c}\% \text { of } \\
\text { Urban } \\
\text { residents } \\
\text { with } \\
\text { organism } \\
\text { to total } \\
\text { patients }\end{array}$ & $\begin{array}{l}\% \text { of } \\
\text { urban } \\
\text { residents } \\
\text { with } \\
\text { organism } \\
\text { to urban } \\
\text { patients }\end{array}$ & $\begin{array}{l}\text { Number of } \\
\text { rural } \\
\text { residents } \\
\text { having } \\
\text { organism }\end{array}$ & $\begin{array}{c}\% \text { of } \\
\text { rural } \\
\text { residents } \\
\text { with } \\
\text { organism } \\
\text { to total } \\
\text { patients }\end{array}$ & $\begin{array}{c}\% \text { of rural } \\
\text { residents } \\
\text { with } \\
\text { organism } \\
\text { to rural } \\
\text { patients }\end{array}$ & \\
\hline Staph. aureus (11) & 6 & 54.5 & 33.3 & 5 & 45.5 & 41.7 & 0.643 \\
\hline Kocuria rosea $(10)$ & 6 & 60 & 33.3 & 4 & 40 & 33.3 & 1.0 \\
\hline$\overline{\text { Diphteroids (10) }}$ & 7 & 70 & 38.9 & 3 & 30 & 25 & 0.429 \\
\hline Strept. pneumoniea (8) & 4 & 50 & 22.2 & 4 & 50 & 33.3 & 0.500 \\
\hline D. nishinomiyaensis (2) & 1 & 50 & 5.6 & 1 & 50 & 8.3 & 0.765 \\
\hline CONS staph (1) & 0 & 0 & 0 & 1 & 100 & 8.3 & 0.213 \\
\hline Kocuria varians (1) & 0 & 0 & 0 & 1 & 100 & 8.3 & 0.213 \\
\hline Kytococcus sedentarius (1) & 1 & 100 & 5.6 & 0 & 0 & 0 & 0.406 \\
\hline Acinetobacter (1) & 0 & 0 & 0 & 1 & 100 & 8.3 & 0.213 \\
\hline Granulicatella elegans (2) & 2 & 100 & 11.1 & 0 & 0 & 0 & 0.232 \\
\hline Candida (1) & 1 & 100 & 5.6 & 0 & 0 & 0 & 0.406 \\
\hline Anthracoids (1) & 0 & 0 & 0 & 1 & 100 & 8.3 & 0.213 \\
\hline
\end{tabular}

D. nishinomiyaensis: Dermacoccus nishinomiyaensis; N: number.

Table 8: Composition of microbiome nasopharyngeal swabs of healthy controls according to residence.

\begin{tabular}{|c|c|c|c|c|c|c|c|}
\hline \multirow[b]{2}{*}{$\begin{array}{l}\text { Organism } \\
\text { (number in both urban } \\
\text { and rural patients) }\end{array}$} & \multicolumn{3}{|c|}{ Urban Controls $(\mathrm{N}=17)$} & \multicolumn{3}{|c|}{ Rural Controls $(\mathrm{N}=13)$} & \multirow[b]{2}{*}{$P$ value } \\
\hline & $\begin{array}{l}\text { Number of } \\
\text { Urban } \\
\text { residing } \\
\text { controls } \\
\text { having } \\
\text { organism }\end{array}$ & $\begin{array}{l}\text { \% of } \\
\text { Urban } \\
\text { residing } \\
\text { controls } \\
\text { with } \\
\text { organism } \\
\text { to total } \\
\text { controls }\end{array}$ & $\begin{array}{c}\% \text { of } \\
\text { urban } \\
\text { residing } \\
\text { controls } \\
\text { with } \\
\text { organism } \\
\text { to urban } \\
\text { controls }\end{array}$ & $\begin{array}{l}\text { Number of } \\
\text { rural } \\
\text { residing } \\
\text { controls } \\
\text { having } \\
\text { organism }\end{array}$ & $\begin{array}{c}\% \text { of } \\
\text { rural } \\
\text { residing } \\
\text { controls } \\
\text { with } \\
\text { organism } \\
\text { to total } \\
\text { controls }\end{array}$ & $\begin{array}{l}\% \text { of rural } \\
\text { residing } \\
\text { controls } \\
\text { with } \\
\text { organism } \\
\text { to rural } \\
\text { controls }\end{array}$ & \\
\hline Staph. aureus (11) & 6 & 66.7 & 35.3 & 3 & 33.3 & 23.1 & 0.469 \\
\hline Kocuria rosea $(10)$ & 5 & 55.6 & 29.4 & 4 & 44.4 & 30.8 & 0.936 \\
\hline Diphteroids (10) & 4 & 50 & 23.5 & 4 & 50 & 30.8 & 0.657 \\
\hline Strept. pneumoniea (8) & 4 & 66.7 & 23.5 & 2 & 33.3 & 15.4 & 0.580 \\
\hline D. nishinomiyaensis (2) & 2 & 40 & 11.8 & 3 & 60 & 23.1 & 0.410 \\
\hline CONS staph (1) & 0 & 0 & 0 & 1 & 100 & 7.7 & 0.245 \\
\hline Kocuria varians (1) & 0 & 0 & 0 & 1 & 100 & 7.7 & 0.245 \\
\hline Kytococcus sedentarius (1) & 0 & 0 & 0 & 1 & 100 & 7.7 & 0.245 \\
\hline Acinetobacter (1) & 6 & 66.7 & 35.3 & 3 & 33.3 & 23.1 & 0.469 \\
\hline Granulicatella elegans (2) & 5 & 55.6 & 29.4 & 4 & 44.4 & 30.8 & 0.936 \\
\hline Candida (1) & 4 & 50 & 23.5 & 4 & 50 & 30.8 & 0.657 \\
\hline Anthracoids (1) & 4 & 66.7 & 23.5 & 2 & 33.3 & 15.4 & 0.580 \\
\hline
\end{tabular}

D. nishinomiyaensis: Dermacoccus nishinomiyaensis; N: number.

Presence of $K$. rosea was more in younger patients, those with more severe asthma, numbers of medications used, asthma hospitalizations, as well as those with a history of NICU admission $(\mathrm{p}=0.012,0.02,0.034,0.006$ and 0.01 respectively).

There was no statistically significant difference in microbiome composition according to residential distribution among both patient (Table 7) and control (Table 8) groups. Figure 1 shows the composition of the microbiome in both asthmatic and control groups as well as in different asthma severities. 


\section{Discussion}

The spectrum of the nasal microbiome composition seems to be unique on an individual level among both the studied healthy children and those who suffer from bronchial asthma. There was a significant difference in the overall microbiome composition between patients and controls $(p=0.007)$. This is in accordance with other studies that suggest that dysbiosis of the microbiome increases the risk and severity of asthma $(12,13)$. Some known risk factors that were detected among our studied group of children with asthma are amenable to prevention; $73.33 \%$ of our asthmatic patients were born by Caesarean section (CS). The notorious relation between Caesarian section and asthma is well known (14). Despite the efforts to limit the Caesarian section as a mode of delivery among Egyptian pregnant women, yet it remains at a staggering very high rate of 52\% (15). Moreover, it seems that Egypt is not the only country struggling with high CS delivery modes. CS rates among European countries varies between 16.5\% in Finland to a much higher $54.8 \%$ in Cyprus (16). It was proven that those who are delivered by CS are deprived from colonization by the more physiologic vaginal microbiome (14). Yet, the maternal gut microbiome is variable and depends on a lot of factors related to host detoxification ability, type of foods, types of chemical exposure and its duration, hormones, immune system and other factors (17). It is interesting however that we could not identify a specific microbiome that correlates statistically with Caesarian section. A bigger sample size might be more revealing.

The nasopharyngeal microbiome spectrum of composition was found to be different among those with asthma and the control group $(\mathrm{p}=0.007)$, and even among those with different grades of asthma severity for $K$. rosea $(\mathrm{p}=0.02)$. Our findings confirm the earlier reports of difference in microbiome composition among exacerbated asthma, non-exacerbated asthma, and healthy controls $(12,13)$. Yet, we did not come across a specific microbiome profile except for the combination of Staph. aureus and Strep. pneumoniae which was more common among asthmatic patients $(13.33 \%$ versus no controls, $\mathrm{p}=0.038)$. This is in accordance with several studies that found that presence of Strep. pneumoniae (either with H. influenzae or Staph. aureus) in the nasopharyngeal microbiome is a predictor for wheezing in infants $(18,19)$. Again, it seems that the microbiome is related very much to an endless number of factors that includes diet, quantities, host-metabolism dynamics, antibiotic intake, hormones, and other factors that need to be explored.

Coagulase negative staphylococci (CONS) were detected mainly among the healthy controls (90\% vs $3.33 \%$ in asthmatics, $\mathrm{p}=0.009)$. CONS are normally found on the skin and mucosa including the nasal flora of healthy subjects $(20,21)$. The absence of CONS in the nasopharyngeal microbiome in asthmatics may lead to dysbiosis and negatively affect the development of the T helper immune system leading to an increased risk of asthma (4).

Kocuria rosea, alone and associated with other organisms, was detected among children who suffered from asthma more than in healthy controls, however the difference did not reach statistical significance $(p=0.06)$. It was found to be more pronounced among those with more severe asthma $(\mathrm{p}=0.02)$. Kocuria rosea are gram-positive, catalase-positive and oxidative-positive cocci. Kocuria rosea is known for its ability to biodegrade malachite green and other industrial dyes $(22,23)$. Malachite green is quite abundant among fish as it has been used universally as a therapeutic treatment in aquaculture, and is known to cause pneumoconiosis upon long-standing inhalation. Malachite green is also mutagenic, carcinogenic and genotoxic (24). It causes lipid peroxidation, lung disease and lung adenomas.

It is not clear if the presence of Kocuria rosea is up-regulated in asthmatics to confer protection from the exposure to the previously mentioned pollutants, or acts otherwise among our studied population. Given the unique individual detoxification genomics among people (25), Kocuria rosea might be the sentinel that is over-expressed due to substrate abundance of dyes and toxins that cause disease among the studied children. We cannot ascertain or rule-out this possibility as we did not study the metabolome in our recruited cohort. The metabolome comprises the various spectra of the metabolites that our microbiome handles and survives in (26). We did not study types of foods, food additives, quality of inhaled air and water, as well as the toxins they are exposed to. The metabolome dictates very much the type of microbiome. More studies are needed to verify if the Kocuria rosea is more abundant because of an excessive 
exposure to dyes and toxins in need of detoxification in the nasopharynx of the studied children or because they cause infection or persistent reactive airway disease.

Kocuria rosea was a constituent of the microbiome among our rather younger studied children $(\mathrm{p}=0.012)$. Kocuria rosea is generally reported to be non-pathogenic, yet lately it was reported as a recognized pathogen associated with serious infections among both immune- compromised children, and immuno-competent as well (27). Factors promoting virulence of Kocuria rosea remain to be known, and the factors governing host- Kocuria rosea interaction remains to be known, given the age-dependent remodeling of our immune system $(28,29)$. It is also important to note that our study did not include typing of the Kocuria rosea (30). It is interesting however that the Kocuria rosea belongs to the actinobacteria phylum, that are responsible for biodegradation of organic matter (31). It is important to note that Lactobacilus bifidus; the most important constituent of the neonatal microbiome belongs to the actinobacteria phylum as well (32). More scientific evidence is needed to clarify the role of Kocuria rosea in the nasopharynx of children, what is the substrate/metabolome in need of decomposition that up-regulates Kocuria rosea? Is it a friend or a foe?

We report the absence of a statistically significant difference between the microbiome of those residing in rural and urban areas among our studied children, as opposed to other studies $(5,33)$. This might, again, be because of the small sample size, or maybe because the degree of environmental pollution between both communities is becoming less different from before. This finding is different from the expected view of the hygiene hypothesis, which dictates that the more the subject is exposed to microorganisms earlier in life, the stronger immune system becomes (34). Again, our entire studied cohort belonged to the same less advantaged socio-economic strata. Hence, maybe the implementation of strict hygiene measures is related to socio-economic strata rather than location.

The authors are well aware of the limitations of the study at hand. The most important is the small sample size, which was further fragmented over the wide spectrum of organisms constituting the microbiome. This led to difficulties in the statistical analysis of such small numbers. The lack of assessment of factors comprising the metabolome (nutrition, socioeconomic standard, environment, pollutants, etc) is another limitation but was beyond the means of the study. Whether the VITEK 2 system for organism detection was a less accurate tool for organism detection than genomic detection is another question.

VITEK uses preset known nutrients and biochemical reactions of the microorganism to make the identification. This necessitates a sufficient amount of growth in a growth culture over a period of $18-70$ hours. Depending on the culture conditions, the reactions of the microorganism may vary (35). Again, we excluded patients who received antibiotics in the last two weeks before sampling which is usually enough to reverse the effect on the nasopharyngeal microbiome (36), yet, some studies show that human gut dysbiosis after antibiotics can last up to 2-6 months (37).

The study at hand studied the composition of the nasopharyngeal microbiome in Egyptian children. It paves the road for further research to explore the pediatric nasopharyngeal microbiome in various settings and diseases, and to determine if modifying the nasopharyngeal microbiome would improve the course of patient illness. Whether reshaping the gut microbiome (by using pro- and pre- biotics) would affect the biosis of the nasopharyngeal microbiome is yet another question to be looked into via future research.

\section{Conclusions}

The composition of the nasopharyngeal microbiome in a group of asthmatic Egyptian children was significantly different from their healthy control peers. Coagulase negative staphylococci (CONS) were significantly higher in healthy controls, while a combination of Staph. aureus and Strep. pneumoniae was higher in asthmatic patients. Kocuria rosea was found to be more common among the younger asthmatics, and among children with a more severe asthma. Validation studies in various settings, and trials to assess if inducing eubiosis would favorably affect the disease course are recommended for future research. 


\section{Acknowledgment}

The authors would like to acknowledge the heads, managers and workers in The Department of Clinical and Chemical Pathology, The Pediatric Allergy Unit and Pulmonology including Pulmonary Function Lab, as well as Children's Specialty Hospital management (Faculty of Medicine, Cairo University) for making this work possible.

\section{Author Contributions:}

C.W.S.B.: Conceptualization, methodology, data analysis, writing original draft and editing. M.A.K.: Data analysis, writing original draft, supervising and revising. A.M.S.: Supervising laboratory work, data curation and analysis, investigation and methodology, visualization and revision of writing. M.A.: Data curation and analysis, investigation and methodology, revision of writing. M.G.: Sample collection, data curation and analysis, investigation and methodology. A.K.A.: Conceptualization, methodology, data analysis, revising and writing. All authors reviewed the final manuscript. All authors have read and agreed to the published version of the manuscript.

\section{FUNDING}

Authors declare there was no extramural funding provided for this study.

\section{CONFLICT OF INTEREST}

The authors declare no conflict of interest in connection with the reported study.

\section{References}

1. S. Tenny, M. Varacallo, Evidence Based Medicine. (StatPearls Publishing; Treasure Island (FL), 2020; https://www.ncbi.nlm.nih.gov/books/NBK470182/).

2. Global Initiative for Asthma., Global Strategy for Asthma Management and Prevention (2021), (available at www.ginasthma.org).

3. M. Sokolowska, R. Frei, N. Lunjani, C. A. Akdis, L. O’Mahony, Microbiome and asthma. Asthma Res. Pract. 4, 1 (2018).

4. M. Noval Rivas, T. R. Crother, M. Arditi, The microbiome in asthma. Curr. Opin. Pediatr. 28, 764-771 (2016).

5. N. Ahmed, N. F. Mahmoud, S. Solyman, A. Hanora, Human Nasal Microbiome as Characterized by Metagenomics Differs Markedly Between Rural and Industrial Communities in Egypt. Omics J. Integr. Biol. 23, 573-582 (2019).

6. K. Loverdos, G. Bellos, L. Kokolatou, I. Vasileiadis, E. Giamarellos, M. Pecchiari, N. Koulouris, A. Koutsoukou, N. Rovina, Lung Microbiome in Asthma: Current Perspectives. J. Clin. Med. 8 (2019), doi:10.3390/jcm8111967.

7. S. Radwan, D. Gilfillan, B. Eklund, H. M. Radwan, N. G. El Menofy, J. Lee, M. Kapuscinski, Z. Abdo, A comparative study of the gut microbiome in Egyptian patients with Type I and Type II diabetes. PLOS ONE. 15, e0238764 (2020).

8. H. T. El-Zawawy, S. M. Ahmed, E. A. El-Attar, A. A. Ahmed, Y. S. Roshdy, D. A. Header, Study of gut microbiome in Egyptian patients with autoimmune thyroid diseases. Int. J. Clin. Pract. 75 (2021), doi:10.1111/ijcp.14038.

9. A. M. Aly, A. Adel, A. O. El-Gendy, T. M. Essam, R. K. Aziz, Gut microbiome alterations in patients with stage 4 hepatitis C. Gut Pathog. 8, 42 (2016).

10. World Medical Association, WMA Declaration of Helsinki- Ethical Principles for Medical Research Involving Human Subjects (2013), (available at https://www.wma.net/policiespost/wma-declaration-of-helsinki-ethical-principles-for-medical-research-involving-humansubjects/2013/).

11. National Heart, Lung and Blood Institute (NHLBI): Expert Panel Report 3:, Guidelines for the Diagnosis and Management of Asthma 2007 (EPR-3) (2007), (available at https://www.nhlbi.nih.gov/health-topics/guidelines-for-diagnosis-management-of-asthma.).

12. S. M. Teo, D. Mok, K. Pham, M. Kusel, M. Serralha, N. Troy, B. J. Holt, B. J. Hales, M. L. Walker, E. Hollams, Y. A. Bochkov, K. Grindle, S. L. Johnston, J. E. Gern, P. D. Sly, P. G. Holt, K. E. Holt, M. Inouye, The Infant Nasopharyngeal Microbiome Impacts Severity of Lower Respiratory Infection and Risk of Asthma Development. Cell Host Microbe. 17, 704715 (2015). 
13. M.-L. von Linstow, K. Schønning, A. M. Hoegh, A. Sevelsted, N. H. Vissing, H. Bisgaard, Neonatal airway colonization is associated with troublesome lung symptoms in infants. Am. J. Respir. Crit. Care Med. 188, 1041-1042 (2013).

14. J. Stokholm, J. Thorsen, M. J. Blaser, M. A. Rasmussen, M. Hjelmsø, S. Shah, E. D. Christensen, B. L. Chawes, K. Bønnelykke, S. Brix, M. S. Mortensen, A. Brejnrod, G. Vestergaard, U. Trivedi, S. J. Sørensen, H. Bisgaard, Delivery mode and gut microbial changes correlate with an increased risk of childhood asthma. Sci. Transl. Med. 12, eaax9929 (2020).

15. N. Abdel-Tawab, Oraby D, Hassanein N, El-Nakib S, Cesarian Section Deliveries in Egypt: Trends, practices, perceptions and cost. (2018), (available at https://www.popcouncil.org/uploads/pdfs/2018PGY_CesareanSectionEgypt.pdf).

16. Eurostat, Large differences in share of caesarean births. Surgical operations and procedures performed in hospitals by ICD-9-CM. (2016), (available at https://ec.europa.eu/eurostat/web/products-eurostat-news/-/DDN-20191217-1).

17. S. M. Edwards, S. A. Cunningham, A. L. Dunlop, E. J. Corwin, The Maternal Gut Microbiome During Pregnancy. MCN. Am. J. Matern. Child Nurs. 42, 310-317 (2017).

18. G. Biesbroek, E. Tsivtsivadze, E. A. M. Sanders, R. Montijn, R. H. Veenhoven, B. J. F. Keijser, D. Bogaert, Early respiratory microbiota composition determines bacterial succession patterns and respiratory health in children. Am. J. Respir. Crit. Care Med. 190, 1283-1292 (2014).

19. L. P. Schenck, M. G. Surette, D. M. E. Bowdish, Composition and immunological significance of the upper respiratory tract microbiota. FEBS Lett. 590, 3705-3720 (2016).

20. K. Becker, C. Heilmann, G. Peters, Coagulase-negative staphylococci. Clin. Microbiol. Rev. 27, 870-926 (2014).

21. H. B. Allen, N. D. Vaze, C. Choi, T. Hailu, B. H. Tulbert, C. A. Cusack, S. G. Joshi, The Presence and Impact of Biofilm-Producing Staphylococci in Atopic Dermatitis. JAMA Dermatol. 150, 260 (2014).

22. G. K. Parshetti, S. Parshetti, D. C. Kalyani, R. Doong, S. P. Govindwar, Industrial dye decolorizing lignin peroxidase from Kocuria rosea MTCC 1532. Ann. Microbiol. 62, 217-223 (2012).

23. G. K. Parshetti, A. A. Telke, D. C. Kalyani, S. P. Govindwar, Decolorization and detoxification of sulfonated azo dye methyl orange by Kocuria rosea MTCC 1532. J. Hazard. Mater. 176, 503-509 (2010).

24. EFSA Panel on Contaminants in the Food Chain (CONTAM), Malachite green in food. EFSA J. 14 (2016), doi:10.2903/j.efsa.2016.4530.

25. S. Caito, L. G. Costa, M. Aschner, in Reference Module in Biomedical Sciences (Elsevier, 2014; https://linkinghub.elsevier.com/retrieve/pii/B9780128012383002099), p. B9780128012383003000.

26. H. Farne, H. T. Groves, S. K. Gill, I. Stokes, S. McCulloch, E. Karoly, M.-B. Trujillo-Torralbo, S. L. Johnston, P. Mallia, J. S. Tregoning, Comparative Metabolomic Sampling of Upper and Lower Airways by Four Different Methods to Identify Biochemicals That May Support Bacterial Growth. Front. Cell. Infect. Microbiol. 8, 432 (2018).

27. J. S. Moreira, A. G. L. Riccetto, M. T. N. da Silva, M. M. dos S. Vilela, Study Group Centro Médico de Campinas/Franceschi Medicina Laboratorial, Endocarditis by Kocuria rosea in an immunocompetent child. Braz. J. Infect. Dis. Off. Publ. Braz. Soc. Infect. Dis. 19, 82-84 (2015).

28. S. Sakata-Kaneko, Y. Wakatsuki, Y. Matsunaga, T. Usui, T. Kita, Altered Th1/Th2 commitment in human CD4+ T cells with ageing. Clin. Exp. Immunol. 120, 267-273 (2000).

29. A. Berger, Th1 and Th2 responses: what are they? BMJ. 321, 424 (2000).

30. M. Gholami, Z. Etemadifar, M. Bouzari, Isolation a new strain of Kocuria rosea capable of tolerating extreme conditions. J. Environ. Radioact. 144, 113-119 (2015).

31. P. Chen, L. Zhang, X. Guo, X. Dai, L. Liu, L. Xi, J. Wang, L. Song, Y. Wang, Y. Zhu, L. Huang, Y. Huang, Diversity, Biogeography, and Biodegradation Potential of Actinobacteria in the Deep-Sea Sediments along the Southwest Indian Ridge. Front. Microbiol. 7, 1340 (2016).

32. J.-H. Lee, D. J. O'Sullivan, Genomic insights into bifidobacteria. Microbiol. Mol. Biol. Rev. MMBR. 74, 378-416 (2010).

33. V. K. Gupta, S. Paul, C. Dutta, Geography, Ethnicity or Subsistence-Specific Variations in Human Microbiome Composition and Diversity. Front. Microbiol. 8, 1162 (2017).

34. M. Scudellari, News Feature: Cleaning up the hygiene hypothesis. Proc. Natl. Acad. Sci. U. S. A. 114, 1433-1436 (2017). 
35. Nelson Labs, Vitek or Genetic ID Testing: What They Are and How to Decide (2013), (available at https://www.nelsonlabs.com/vitek-or-genetic-id-testing-what-they-are-andhow-to-decide/.).

36. V. R. Ramakrishnan, J. Holt, L. F. Nelson, D. Ir, C. E. Robertson, D. N. Frank, Determinants of the Nasal Microbiome: Pilot Study of Effects of Intranasal Medication Use. Allergy Rhinol. 9, 215265671878951 (2018).

37. K. T. Elvers, V. J. Wilson, A. Hammond, L. Duncan, A. L. Huntley, A. D. Hay, E. T. van der Werf, Antibiotic-induced changes in the human gut microbiota for the most commonly prescribed antibiotics in primary care in the UK: a systematic review. BMJ Open. 10, e035677 (2020).

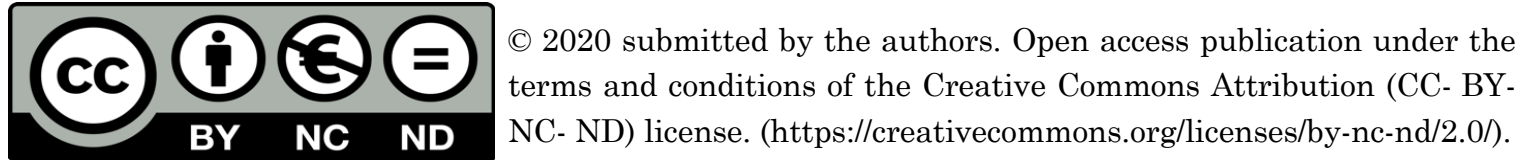

